\title{
Solar powered peltier cooling storage for vaccines in rural areas
}

\author{
Henning Buitendach, Immanuel N. Jiya and Rupert Gouws \\ North-West University, Potchefstroom, South Africa
}

\begin{abstract}
Article Info
Article history:

Received Apr 20, 2019

Revised Jun 15, 2019

Accepted Jul 23, 2019

\section{Keywords:}

PV Energy

Renewable Energy

Vaccine Storage

ABSTRACT

The research presented in this paper proposes a new design of a vaccine cooling and storage unit that can keep vaccines in the cold chain $\left(2^{\circ} \mathrm{C}\right.$ to $8^{\circ} \mathrm{C}$ ). This design was done to facilitate effective completion of the African vaccination week. The cooling and storage unit was designed to be compact, portable, well isolated and to make use of a PV solar energy system as a source of electricity. The cooling unit makes use of a Liquid to Air thermoelectric cooling module connected to some tubing and a liquid pump to cool the inside of the cooling unit. The design process also included designing a control system that controls the temperature inside the cooling holder and a monitoring system to monitor the battery voltage and capacity. The system also has a user interface that displays the temperatures inside and outside of the cooling holder, as well as the battery voltage and capacity. The cooling system successfully developed was able to keep vaccines in the cold chain for up to three days, the system could control the temperature of the vaccines with an accuracy of $1{ }^{\circ} \mathrm{C}$ and was small and portable, but still had enough room to house up to 250 vaccines.
\end{abstract}

Copyright @ 2020 Institute of Advanced Engineering and Science. All rights reserved.

Corresponding Author:

Jiya Immanuel Ninma,

North-West University, Potchefstroom, South Africa.

Email: immanueljiya@ieee.org

\section{INTRODUCTION}

The African vaccination week, organized by the World Health Organization (WHO) each year, has the potential to drastically lower the amount of deaths among young children in Africa. According to the latest study done by the WHO (World Health Organization) in 2013 around 2.9 million children under the age of 5 years died in the WHO's African region[1]. People living in these rural parts of Africa do not get necessary medical attention and most of the time are not informed enough either. They do not have the knowledge to know when their children are ill and even if they do, they do not have any resources like a clinic or doctor to support them. The WHO state that the main cause of these deaths are pneumonia, diarrhoea, malaria and HIV [1].

Immunization is one of the most cost-effective and successful ways that some of these infectious diseases can be stopped to save millions of lives[2]. Each year during World Immunization Week, the WHO Regional Office for Africa coordinates the African Vaccination Week. The goal of this program, led by the WHO, is to save lives and to raise awareness under the people in these parts of Africa. For this program to be successful the vaccines used during the immunization program need to stay in the cold chain system. The cold chain system refers to the temperature controlled storage and transport of vaccines that is needed for these vaccines to arrive at the patient in a potent state. The health workers that should be concentrating on the vaccination program spend a lot of time and energy on trying to keep these vaccines in the cold chain. The required temperature that a vaccine should have to stay in the cold chain is $2^{\circ} \mathrm{C}$ up to $8^{\circ} \mathrm{C} \mathrm{[3]}$.

Having a cooling device that can keep the vaccines at the correct temperature will give the health workers the chance to do more vaccinations [4-8]. There is also the problem of the transport of these vaccines 
to these parts in Africa as the journey can be quite long and the vaccines need to stay in the cold chain. These parts of Africa very seldom have access to electricity; thus, they cannot use a standard fridge [9-11]. The numerous improvements to renewable energytechnology, particularly solar energy harnessing and conversion into electrical energyby means of PV panels [12-21], brings about a good opportunity to arrst the grand challenge of electrical energy in rural areas. This being opportunity to solve not only the challenge of vaccine storage but extends to several other thermoelectric applications [22-28].

In previous research $[4-8,10,11,22,23,29]$, attempts have been made to improve the storage condition of vaccines and or other vital medical supplies. However, most of these solutions still posses certain unique shortcoings. Some of the issues still left to be addressed includes the size of the cooling compartment, the energy consumption of the system, the efficiency and the time within which the cold chain temperature requirements can be maintained. Summarily, they are either too large, not energy efficient enough or not able to maintain the cold chain for the time required. There is also the fact thatsome of the systems proposed previously are fragile and hence require a high skilled maintenance to keep thesystem running effectively and efficiently. This level of skilled maintecnance is often not available in rural communities thus posing a crucial question to the economic feasibility of running such systems in rural areas. Some of these systems are also unnesesarily "intelligent" which makes their adoption in rural Africa more difficult than it should due to the dearth of technical know-how [30].

The solution proposed in this research, is a robust vaccine cooling and storage unit that would keep the vaccines in the cold chain. The cooling and storage unit would be kept compact and portable. This cooling holder should make use of a solar power system as a source of electricity. The solution proposed in this research, seeks to improve the size and efficiency of the system while also making it robust but simple enough for easy adoption and maintenance in rural areas.

\section{PROPOSED SOLUTION}

In this design, some of the main technical issues during any vaccination program are addressed. These issues include the cold chain of vaccines during the vaccination program, as well as the energy consumption of the cooling system used [1-3]. The proposed solution consists out of a compact cooling holder that is well isolated and has enough room for several vaccines. The cooling holder will make use of the most energy efficient and stable cooling method. The cooling holder will have control system that would ensure that the temperature stays within the requirements of 2 and $8{ }^{\circ} \mathrm{C}$ and controls the energy supplied and consumed. The cooling holder will be power by a solar power source. This, together with the energy efficient cooling unit that will be used, will minimize the energy usage of the cooling holder. The functional units as in Figure 1 are all of the physical units that are needed to build this cooling system. Each of these units is described in detail in Table 1. A detailed flow diagram of how these units interact and work together as one system is presented in Figure 2.

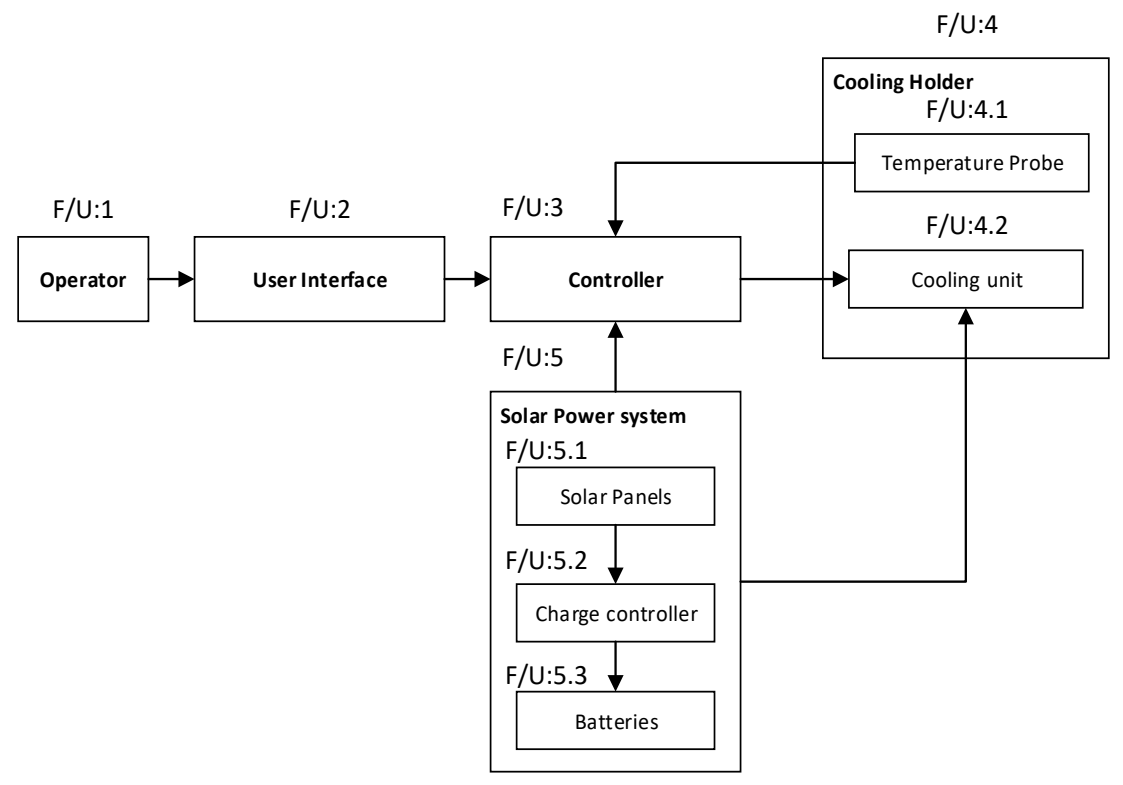

Figure 1. Conceptual design diagram 
The Figure 2 is an illustration of the functional flow of the cooling system. This figure indicates how the temperature and energy control and monitoring of the cooling system will function. When the cooling system is powered on, the controller will start to receive information like the temperature inside the cooling holder, the set temperature by the user, the battery power left, and the energy consumed by the system. This information is then used for temperature and energy monitoring and control.

Table 1. Functional Unit description

\begin{tabular}{|c|c|}
\hline Functional Unit & Detail description \\
\hline 1: Operator & $\begin{array}{l}\text { The operator will interact with the user interface. Information like the desired temperature will be } \\
\text { inserted into the user interface by the operator. }\end{array}$ \\
\hline 2: User interface & $\begin{array}{l}\text { The temperature and energy consumption will be displayed on the user interface. The user will also be } \\
\text { able to set the temperature on this interface. }\end{array}$ \\
\hline 3: Controller & $\begin{array}{l}\text { The controller will receive information from the user interface, solar power system and the } \\
\text { temperature probe. This information will be used to control the temperature by controlling the status } \\
\text { of the cooling unit. The controller will also send information like the temperature and energy } \\
\text { consumption to the user interface. }\end{array}$ \\
\hline 4: Cooling holder & $\begin{array}{l}\text { The cooling holder will isolate the vaccines from the ambient temperature. The cooling unit, } \\
\text { temperature probe, controller and user interface will be mechanically connected to the cooling holder. }\end{array}$ \\
\hline 4.1: Temperature probe & $\begin{array}{l}\text { The temperature probe will capture the temperature inside the cooling holder and send this } \\
\text { information to the controller. }\end{array}$ \\
\hline 4.2: Cooling unit & $\begin{array}{l}\text { The cooling unit will be responsible for maintaining the required temperature inside the cooling } \\
\text { holder. The cooling unit's status will be determined and controlled by the controller. }\end{array}$ \\
\hline 5: Solar Power system & The solar power system will supply the necessary power to the vaccine cooling holder. \\
\hline 5.1: Solar panels & Solar panels will be used to capture renewable energy from the sun. \\
\hline 5.2: Charge controller & $\begin{array}{l}\text { A charge controller will be used to determine the maximum power point of the electricity supplied by } \\
\text { the solar panels. }\end{array}$ \\
\hline 5.3: Batteries & The energy supplied by the solar panels will be stored in the batteries \\
\hline
\end{tabular}

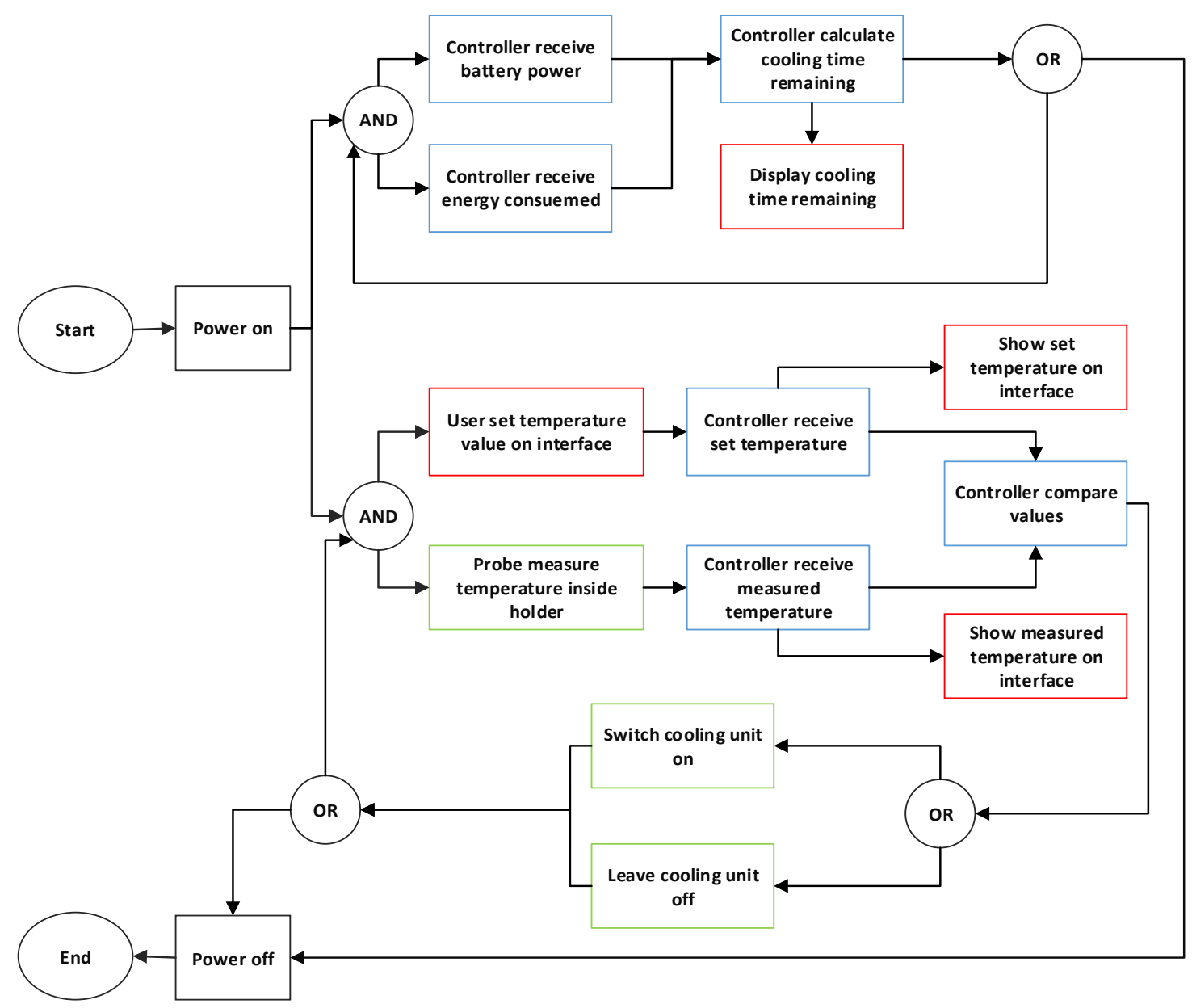

Figure 2. Functional flow diagram 


\section{DESIGN OVERVIEW}

In this section the detail design for the efficient vaccine cooling system is presented. This includes the wiring of the different components, the controlled and monitoring software, the solar power system and how all of the cooling components like the thermoelectric cooling module (TECM), tubing, pump and cooling holder fits together. Simulation results are presented to demonstrate the functionality of the cooling system by using software like SolidWorks, PLC Siemens LOGO! Soft Comfort and PVSyst ${ }^{\circledR}$.

The Liquid to air TECM selected for this project is the LA-115-24-02-0710 by Laird Technologies. This TECM consists of a warm side with a heatsink and a fan attached to it and a cold side with some tubing running through a cold plate [31]. The RTD temperature probe selected for this project is a PT100 probe. One of the reasons for that is the fact that a PLC is selected as the controller. An extension module can be used to connect the PT100 directly to the PLC.

The PLC selected is the Siemens Logo 12/24RC as this is the PLC the university has available. In addition to the Siemens 12/24 RC, an extension module is also required to connect the temperature probes directly to the PLC. An AM2 RTD extension module is selected, with the capability of connecting two Pt100 temperature sensors to it. The condition for the input to the AM2 is a temperature input between $-50^{\circ} \mathrm{C}$ and $200^{\circ} \mathrm{C}$. Figure 3 shows the schematic for the detail design of the PLC's control and monitoring. The cooling holder selected for the efficient vaccine cooling system is the 10 litre cold box produced by Eva Kool. The cold box is shown in the Figure 4 .

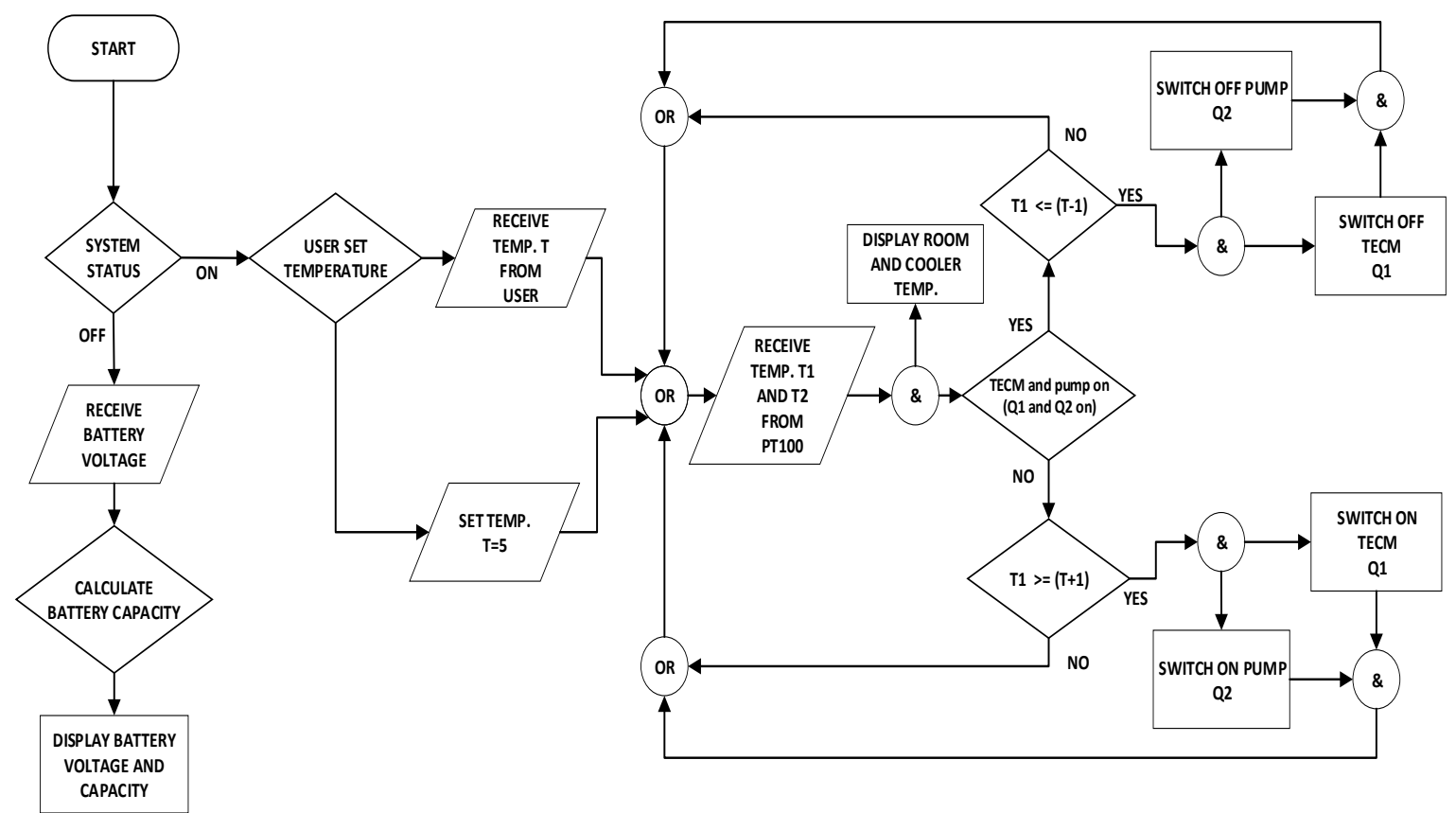

Figure 3. PLC logic flow diagram
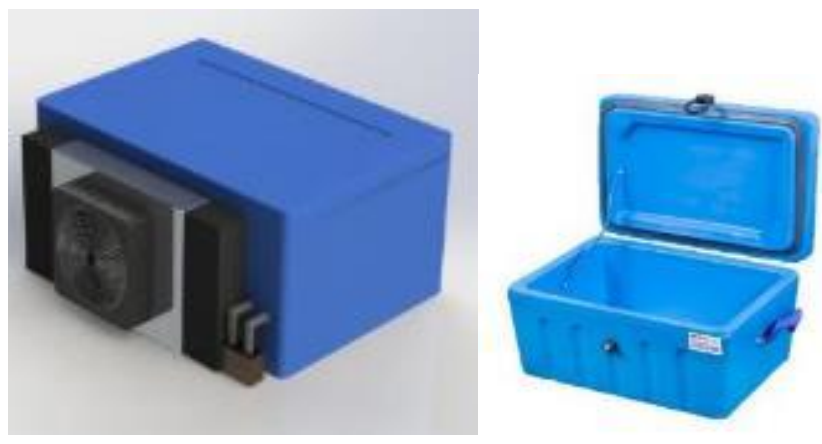

Figure 4. Eva Kool 10 litre cold box 
The main problem in rural areas where the system is to be potentially applied is that there will not always be electricity available to use for the vaccine cooling system, thus a solar power system was designed to be able to supply the vaccine cooling system with power. Two solar power systems were designed; the first was be for a worst-case scenario and the second a more realistic system with a size constrain. The worstcase scenario is that the temperatures are extremely hot, and it is cloudy for up to 3 days. This first step is to determine the maximum energy consumption of the cooling system. The energy consumption of each component is listed in Table 2 as well as the total energy consumption of the system. The maximum energy consumption in watts is $158 \mathrm{~W}$ and the system would thus consume a maximum of $3792 \mathrm{Wh}$ per 24-hour day. The TECM require a input power of $24 \mathrm{~V}$ while the rest of the components require $12 \mathrm{~V}$. The total Watt hours used per day by the cooling system is $3792 \mathrm{Wh}$. The watt hours are then divided by 0.85 to compensate for the battery losses.

$$
\text { Watt }- \text { hours }=\frac{\text { Watt }- \text { hours }}{0.85}=\frac{3792 \mathrm{Wh}}{0.85}=4461 \mathrm{Wh}
$$

Table 2. Maximum energy consumption

\begin{tabular}{ll}
\hline Component & Maximum energy consumption (W) \\
\hline LA-115-24-02-0710 liquid to air TECM & 139 \\
Siemens Logo 12/24RC and AM2 Pt100 module & 2 \\
Pt100 temperature probes & 2 \\
Pump & 15 \\
Total & 158 \\
\hline
\end{tabular}

Watt hours is then converted to amp hours by dividing the watt hours with the nominal voltage of the batteries.

$$
\text { Amp }- \text { hours }=\frac{\text { Watt }- \text { hours }}{24 \mathrm{~V}}=\frac{4461 \mathrm{Wh}}{24 \mathrm{~V}}=185.9 \mathrm{Ah}
$$

The solar power system should also be able to provide energy to the cooling system for up to 3 days with no power provided by the PV panels. The amp hours should thus be multiplied by 3 . This then gives a total of $557.7 \mathrm{Ah}$.

$$
\text { Total battery capacity }(\mathrm{Ah})=185.9 \mathrm{Ah} \times 3=557.7 \mathrm{Ah}
$$

To determine the size of PV panels that are needed to supply enough energy to the cooling system and sufficiently charge the batteries the peak watt $(\mathrm{Wp})$ produced is needed. The $\mathrm{Wp}$ depends on the size of the PV panels as well as the climate of the location the PV panels are situated [32]. The peak watt (Wp) produced by the PV panels for this specific project is calculated by using simulation software PVSyst ${ }^{\circledR}$. This software is used because of its ability to use any desired location to calculate the peak watt produced as well as the battery capacity required. Potchefstroom was chosen as the location to simulate the available solar energy as this would most likely be to location where the solar system is tested. PVSyst ${ }^{\circledR}$ calculated the peak watt (Wp) produced to be $779 \mathrm{Wp}$ and a battery capacity of $558 \mathrm{Ah}$. The electrical characteristics of the ReneSola Virtus II $260 \mathrm{~W}$ solar panel that was used is presented in [33]. The charge controller is responsible for maximum power point tracking to ensure that the PV panels are used to their full potential. The short circuit current of the PV panels that are selected is 8.95A each. This short circuit current is obtained at ambient temperature and can be up to $20 \%$ more in high temperatures.

$$
\begin{aligned}
& \text { Short circuit current total }=8.95 \mathrm{~A} \times 3 \text { panels }=26.85 \mathrm{~A} \\
& \text { Short circuit current total }=26.85 \mathrm{~A}+(26.85 \mathrm{~A} \times 20 \%)=32.22 \mathrm{~A}
\end{aligned}
$$

From this calculation, it is implied that a charge controller should have a rating of at least $32.22 \mathrm{~A}$. Due to standard sizes of charge controller, a $40 \mathrm{~A}, 24 \mathrm{~V}$ charge controller is selected for this solar power system.

The second scenario is a system that will be mounted to an automotive vehicle, thus this system should be relatively small. The system consists of only one solar panel that will be fitted to the roof of the automotive vehicle and a much smaller battery bank also fitted to the vehicle. The idea of this system is that the batteries will be pre-charged before the health workers sets off for the vaccination programs. The 
batteries will also be charging using a PV panel while the health workers are busy with the vaccination week in locations without electricity. The PV panel will be the ReneSola Virtus II $260 \mathrm{~W}$ panel, but only one rather than three like in the system above. Two $45 \mathrm{Ah}, 12 \mathrm{~V}$ batteries will be used, connected in series to form a 24 $\mathrm{V}$ battery bank. The size of the charge controller needed for this system is calculated using the short circuit current of the solar panel. The sort circuit current is $8.95 \mathrm{~A}$ at ambient temperature and can rise up to $20 \%$ in higher temperatures.

Short circuit current total $=8.95 \mathrm{~A}+(8.95 \mathrm{~A} \times 20 \%)=10.74 \mathrm{~A}$ controller.

Due to the standard sizes of solar charge controllers, this system will use a $15 \mathrm{~A}, 24 \mathrm{~V}$ charge

\section{IMPLEMENTATION AND RESULTS}

The integrated system consists of the cooling holder, PLC and electronic circuit. Figure 5 shows how the PLC and electronics, the cooling holder and the PT100 sensors are integrated together. The cooling holder consists of the TECM, pump, liquid coolant and tubing.

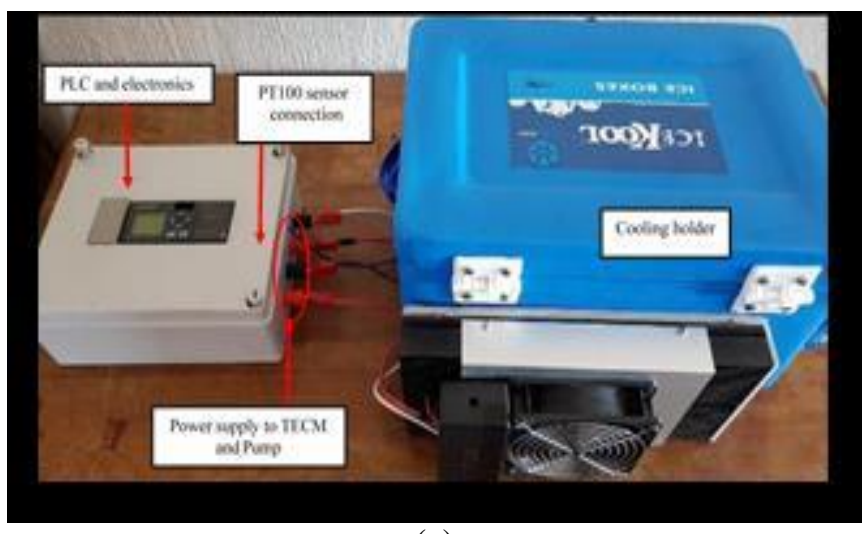

(a)

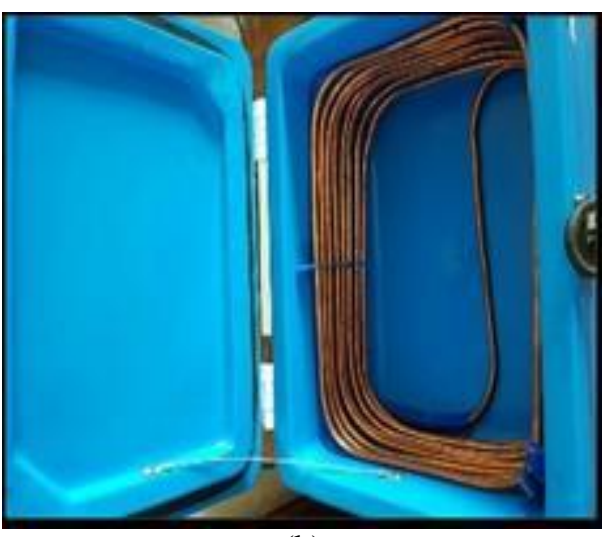

(b)

Figure 5. Descriptive pictorial view of the implemented system (a) integrated system and (b) cross section of the implemented cooling box

The Vaccine cooling system is evaluated and tested to ensure that the objectives of this project are achieved. The most important objective of this project is to ensure that the vaccines stay in the cold chain. The equipment used to test the Vaccine cooling system included a DC power supply with a constant voltage of $24 \mathrm{~V}$, a multi-meter, a Fluke Thermal imager and the PT100 temperature sensors.

The system was tested to evaluate the temperature change in the cooling holder, the time required for the temperature change and the energy usage of the system. The PT-100 temperature sensor has been validated in previous research [34-36], therefore, there is no need presenting the validation results in this paper once it was confirmed to be working effectively by verifying the temperature values using an external equipment. Figure 6 represents the temperature of the cooling system without a load over a period of 100 minutes. The figure shows the time that is required by the system to reach a temperature of $3{ }^{\circ} \mathrm{C}$. At $3{ }^{\circ} \mathrm{C}$ the system was switched off to measure the time the system will keep its temperature and stay in the required temperature range of $2{ }^{\circ} \mathrm{C}$ to $8{ }^{\circ} \mathrm{C}$.

Matlab $^{\circledR}$ was used to fit a curve to the data obtained from this test. The curve fitted to the data points has a R-square value of 0.9933 and can thus be used as an accurate representation of the air temperature over time in the cooling holder. The air temperature inside the cooling holder can be represented with the polynomial function of $\mathrm{T}$ in ${ }^{\circ} \mathrm{C}$,

$$
T(t)=p_{1} t^{3}+p_{2} t^{2}+p_{3} t+p_{4}
$$

Where, $p_{1}=1.179 \times 10^{-5}, p_{2}=0.001523, p_{3}=-0.4054, p_{4}=20.62$ and $\mathrm{t}$, the time in minutes. This can be used for further work on this project in the future to determine the air temperature after a certain amount of time. 


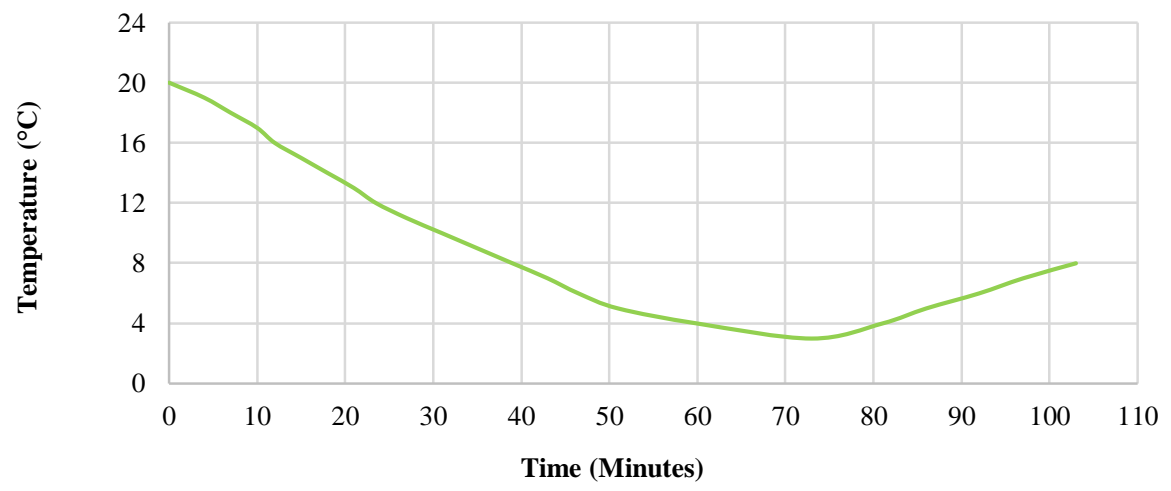

Figure 6. No-Load temperature test data plot

From the equation calculated making use of $\mathrm{Matlab}^{\circledR}$, the time required to cool the system down from any starting temperature can be determined. The value of $p_{4}$ is the starting temperature and can be changed to the starting temperature of the cooling system. For instance, if the starting temperature is $35{ }^{\circ} \mathrm{C}$ and the system needs to be cooled down to a desired temperature of $5{ }^{\circ} \mathrm{C}$, the time required by the system is,

$$
\begin{aligned}
& T(t)=p_{1} t^{3}+p_{2} t^{2}+p_{3} t+p_{4} \\
& \text { Where; } p_{1}=1.179 \times 10^{-5}, p_{2}=0.001523, p_{3}=-0.4054, p_{4}=35 \text { thus, } T(t)=5^{\circ} \mathrm{C} \\
& 5=\left(1.179 \times 10^{-5}\right) t^{3}+(0.001523) t^{2}-0.4054 t+35 \\
& t=94 \text { minutes }
\end{aligned}
$$

Although this might not be the exact time as there are other external influences like humidity and the presence or absence of direct sunlight that will affect this time, this is a good starting point. In the case of the loaded temperature test, the purpose of this test is to determine the temperature of the heat load inside the cooling holder. This cooling system is designed to keep vaccines in the cold chain $\left(2{ }^{\circ} \mathrm{C}\right.$ to $\left.8{ }^{\circ} \mathrm{C}\right)$ and it is thus important to firstly test to see if the system can do so and secondly to determine how efficient the system is.

One litre of water placed in a glass container is used to represent the heat load of the vaccines that this system will be used for. One vaccine has the volume of $8 \mathrm{ml}$ and one litre of water is thus equivalent to about 125 vaccines. Although the vaccines that will be placed inside the cooling holder will already be between the temperatures of 2 and $8^{\circ} \mathrm{C}$, the water temperature was $20^{\circ} \mathrm{C}$ when it was placed in the cooling holder.

The load test was done over a period of 3 hours. From this test the time required to reach a certain temperature is obtained as well as the system capability to maintain a certain decried temperature. The temperature is measured with the thermal imager every two to five minutes in this 3-hour period. For this specific test the PLC was set to maintain a temperature between 4 and $5{ }^{\circ} \mathrm{C}$. Although the cold chain is between 2 and $8^{\circ} \mathrm{C}$, the temperature recommended by the WHO is $5{ }^{\circ} \mathrm{C}$ [3]. The reason the PLC is set to control the temperature precise to one degree Celsius and not lower, at for instance $0.5{ }^{\circ} \mathrm{C}$, is to avoid the TECM from switching on and off too often. In Figure 7 the green line represents the ambient temperature and the blue line the load temperature. The red dotted lines are the limits of the cold chain system. The figure shows that when the load temperature reached $4{ }^{\circ} \mathrm{C}$ the system is switched off and when the load temperature then again reached $5{ }^{\circ} \mathrm{C}$ the system is switched on again.

One of the objectives of this project was to make use of an alternative power source as the parts of Africa where a system like this will be used, do not always have access to electricity. The energy usage of the system is thus very important. A test was done to measure the energy usage of the system for each hour of a regular early summer day in Potchefstroom. This may not be the exact usage of the system in other parts of Africa at different times of the year, but it will give a close representation. If the TECM is switched on the system will need a current of $5.42 \mathrm{~A}$ at a voltage of $24 \mathrm{~V}$. This gives an energy usage of $130 \mathrm{~W}$. If the TECM is switched off, only the PLC will consume energy which is only $2 \mathrm{~W}$. The energy consumption of the system for each hour is thus calculated as follow. If the system is switched on for $40 \mathrm{~min}$ of the hour and off for $20 \mathrm{~min}$, the average usage for that hour is, 


$$
\text { Energy consumption }=130\left(\frac{40}{60}\right)+2\left(\frac{20}{60}\right)=87.33 \mathrm{~W}
$$

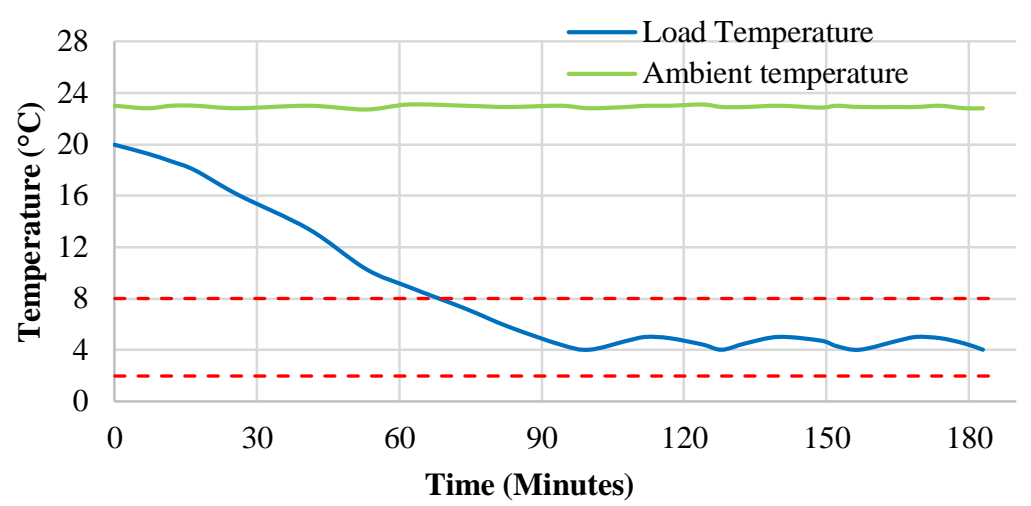

Figure 7. Load temperature test data plot

The average energy consumption of the vaccine cooling system for each hour can be seen in Figure 8. The energy consumption is plotted together with an educated representation of the energy supply of one 260W PV panel over a period of 24 hours. The representation of the energy supply is constructed making use of PVSyst ${ }^{\circledR}$ and the Renesola Virtus II 260W PV panel data sheet. The energy consumption shown on this graph is thus measured data while the energy supply is only a representation of the size limit solar system.

The worst case solar power system is designed to keep the vaccine cooling system powered up for as long as necessary, even when there is no sun light for three days. The size limit solar power system however only consists of one 260W PV panel and one 150 Ah battery, which will only be able to supply power to the vaccine cooling system for a limited time. The running time for the system, when using the second solar power system can be calculated making use of this data.

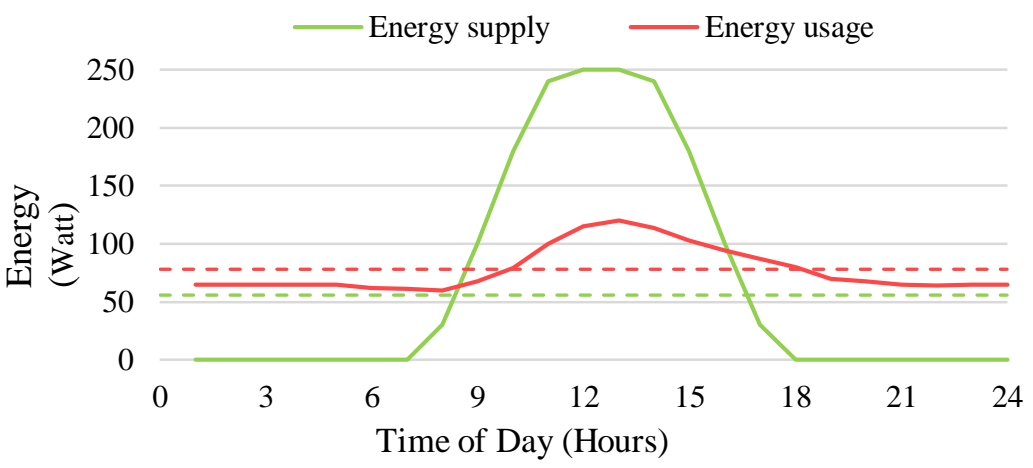

Figure 8. Energy consumption vs Energy usage

Working with this measured energy consumption of the vaccine cooling system together with the Size limit PV system as discussed above, the running time of the system can now be calculated using the data as represented in Figure 8. The first step is to determine the available Watt-hours of the size limit PV system pre- charged battery.

$$
\text { Amp }- \text { hours }=\frac{\text { Watt }- \text { hours }}{\text { Battery Voltage }}=\frac{150 \mathrm{Ah}}{12 \mathrm{~V}}=1.8 \mathrm{kWh}
$$

The $260 \mathrm{~W}$ PV panel used for this system will produce $1.3 \mathrm{kWh}$ of energy per day if situated in Potchefstroom. This is obtained from Figure 8 or more directly from the simulation software PVSyst ${ }^{\circledR}$. The cooling system requirement is $1896 \mathrm{Wh}$ per day as an average energy consumption of $78 \mathrm{~W}$ per hour is 
obtained from this test. This gives a shortage of $596 \mathrm{Wh}$ per day that will have to be supplied by the capacity stored in the pre- charged battery. The system thus has a running time of, 3 days.

Thus, cooling system will be able to run for three days if the Size limit PV system, (one PV panel and one battery), is used and the cooling system is kept at an average temperature of $23^{\circ} \mathrm{C}$ over the three days. The accuracy of the system monitoring was tested by comparing the values shown on the user interface with values measured with external equipment.

\section{CONCLUSION}

The system presented in this work is a new and tailored cooling system for keeping vaccines in the cold chain which was to be applicable for developing countries where availability of energy in the rural areas is still a huge challenge. This research hopes to solve the problem as the vaccines will be kept in the cold chain in a small and portable cooling system. The system was be able to control and monitor the temperature of the storage system. The design process included designing an innovative way of using a liquid to air TECM to ensure that this cooling unit uses its full potential with as little as possible energy loss. When working with vaccines, the temperature as well as the systems capability to maintain that temperature is very important, therefore, a user interface with the ability to show the temperature, battery voltage as well as the battery capacity remaining was implemented.

The objectives which were achieved by this research include, being able to keep vaccines in the cold chain for upto 72 hours (3day), temperature control accuracy of $1{ }^{\circ} \mathrm{C}$, portability and capacity to house upto to 250 vials of vaccine. The system developed although being robust is very user-friendly and the maintenance cost is also less since the system is robust enough not to need a high skilled personel to operate andmaintain.

\section{REFERENCES}

[1] World Health Organization, Global Vaccine Action Plan 2011-2020. World Health Organization, 2013.

[2] World Health Organization, "World Immunization Week 2017," World Health Organization, 2017.

[3] World Health Organization, Immunization in practice: a practical guide for health staff - 2015 update. China: World Health Organization, 2015.

[4] S. Monteleone, M. Sampaio, and R. F. Maia, "A novel deployment of smart Cold Chain system using 2G-RFIDSys temperature monitoring in medicine Cold Chain based on Internet of Things," in 2017 IEEE International Conference on Service Operations and Logistics, and Informatics (SOLI), 2017, pp. 205-210.

[5] S. Jones, "Sure Chill Refrigeration Technology: Improving the Cold Chain in the Developing World," in 2011 IEEE Global Humanitarian Technology Conference, 2011, pp. 205-207.

[6] R. Anderson et al., "Supporting immunization programs with improved vaccine cold chain information systems," in IEEE Global Humanitarian Technology Conference (GHTC 2014), 2014, pp. 215-222.

[7] J. M. Li, M. Friend, A. Miller, and S. Stone, "A SDD and PCM solution for vaccine storage and outreach," in 2016 IEEE Global Humanitarian Technology Conference (GHTC), 2016, pp. 555-562.

[8] M. Friend and S. Stone, "Challenging requirements in resource challenged environment on a time challenged schedule: A technical solution to support the cold chain for the VSV-Zebov (Merck) Ebola vaccine in Sierra Leone Guinea," in 2015 IEEE Global Humanitarian Technology Conference (GHTC), 2015, pp. 372-376.

[9] A. S. Talhar and S. B. Bodkhe, "The global survey of the electrical energy distribution system: a review," International Journal of Electrical and Computer Engineering (IJECE), vol. 9, no. 4, pp. 2247-2255, 2019.

[10] J. A. Gastelo-Roque and A. Morales-Acevedo, "Design of a photovoltaic system using thermoelectric Peltier cooling for vaccines refrigeration," in 2017 IEEE MIT Undergraduate Research Technology Conference (URTC), 2017, pp. 1-4.

[11] K. Srinivasan and T. A. Kattakayam, "Robust controller for an autonomous small refrigeration unit," IEE Proceedings - Science, Measurement and Technology, vol. 146, no. 3, pp. 159-163, May 1999.

[12] A. Pradhan and B. Panda, "Experimental Analysis of Factors Affecting the Power Output of the PV Module," International Journal of Electrical and Computer Engineering (IJECE), vol. 7, no. 6, p. 3190, Dec. 2017.

[13] A. Y. Al-Rawashdeh, O. Albarbarawi, and G. Qaryouti, "Response of Polycrystalline Solar Cell Outputs to Visible Spectrum and other Light Sources-a Case Study," International Journal of Electrical and Computer Engineering (IJECE), vol. 8, no. 6, p. 4096, Dec. 2018.

[14] A. A. Abdulrazzaq and A. Hussein Ali, "Efficiency Performances of Two MPPT Algorithms for PV System With Different Solar Panels Irradiancess," International Journal of Power Electronics and Drive Systems (IJPEDS), vol. 9, no. 4, p. 1755, Dec. 2018.

[15] M. H. Alomari, J. Adeeb, and O. Younis, "PVPF tool: an automatedWeb application for real-time photovoltaic power forecasting," International Journal of Electrical and Computer Engineering (IJECE), vol. 9, no. 1, p. 34, Feb. 2019.

[16] S. Hadisaputra, M. Zohri, H. Hardani, and A. Fudholi, "Improvement Potential and Exergy Analyses of Photovoltaic Thermal with and without $\nabla$-absorber Collector," International Journal of Power Electronics and Drive Systems (IJPEDS), vol. 9, no. 4, p. 1792, Dec. 2018.

[17] A. T, I. Jagadeesh, and I. V, "Design and implementation of modified multilevel sepic converter for PV based 
apllications," Indonesian Journal of Elec. Eng. and Comp. Sci. (IJEECS), vol. 14, no. 3, p. 1125, Jun. 2019.

[18] N. Farhana Mohd Razali, A. Fudholi, M. Hafidz Ruslan, and K. Sopian, "Electrical characteristic of photovoltaic thermal collector with water-multiwalled carbon nanotube nanofluid flow," Indonesian Journal of Electrical Engineering and Computer Science (IJEECS), vol. 13, no. 1, p. 324, Jan. 2019.

[19] G. A. Mani and A. K. Parvathy, "High gain boost converter with modified voltage multiplier for stand alone PV system," Indonesian Journal of Elec. Eng. and Comp. Sci. (IJEECS), vol. 14, no. 1, p. 185, Apr. 2019.

[20] N. Shahirah Binti Rukman et al., "Electrical and thermal efficiency of air-based photovoltaic thermal (PVT) systems: an overview," Indonesian Journal of Elec. Eng. and Comp. Sci. (IJEECS), vol. 14, no. 3, p. 1134, Jun. 2019.

[21] E. Roslan and A. Razak, "Performance effect of applying paraffin wax on solar photovoltaic backplate," Indonesian Journal of Elec. Eng. and Comp. Sci. (IJEECS), vol. 14, no. 1, p. 375, Apr. 2019.

[22] P. Attavane, G. B. Arjun, R. Radhakrishna, and S. R. Jadav, "Solar powered portable food warmer and cooler based on peltier effect," in 2017 2nd IEEE International Conference on Recent Trends in Electronics, Information \& Communication Technology (RTEICT), 2017, pp. 1975-1978.

[23] Shuwang Chen, Jun Zuo, and Dan Xie, "Design of solar power semiconductor refrigerator," in 2010 8th World Congress on Intelligent Control and Automation, 2010, pp. 419-423.

[24] A. H. M. Alamwgani, A. T. Hindi, M. Irfan, H. Alghamidi, and S. Rahman, "Design and development of mobile charging system using thermoelectricity," Indonesian Journal of Elec. Eng. and Comp. Sci. (IJEECS), vol. 14, no. 2, p. 972, May 2019.

[25] S. K. A. Khalid, N. S. Che Dan, N. A. Samsudin, M. S. Aripin, and N. A. A. Nordin, "Autonomous coop cooling system using renewable energy and water recycling," Indonesian Journal of Elec. Eng. and Comp. Sci. (IJEECS), vol. 13, no. 3, p. 1303, Mar. 2019.

[26] E. Roslan and I. Hassim, "Solar pv system with pulsating heat pipe cooling," Indonesian Journal of Elec. Eng. and Comp. Sci. (IJEECS), vol. 14, no. 1, p. 311, Apr. 2019.

[27] M. I. A. Arafa and E.-S. S. A. Said, "A Different Visions for Uninterruptible Load using Hybrid Solar-Grid Energy," International Journal of Power Electronics and Drive Systems (IJPEDS), vol. 10, no. 1, p. 381, Mar. 2019.

[28] A. Fudholi et al., "Solar Drying Technology in Indonesia: an Overview," International Journal of Power Electronics and Drive Systems (IJPEDS), vol. 9, no. 4, p. 1804, Dec. 2018.

[29] K. G. B. Arjun, B. G. Pruthviraj, K. Y. K. Chethan, and P. Rashmi, "Design and implementation of peltier based solar powered portable refrigeration unit," in 2017 2nd IEEE International Conference on Recent Trends in Electronics, Information \& Communication Technology (RTEICT), 2017, pp. 1971-1974.

[30] I. Saritas and M. Okay, "Design of portable medical cooler with artificial intelligent control," in International Conference on challenges in IT, Engineering and Technology (ICCIET'2014), 2014, pp. 39-44.

[31] Laird-Technologies, "LA PowerCool Series, LA-115-24-02 Thermoelectric Assembly," 2010.

[32] Leonics, "How to Design Solar PV System - Guide for sizing your solar photovoltaic system." [Online]. Available: http://www.leonics.com/support/article2_12j/articles2_12j_en.php. [Accessed: 13-May-2019].

[33] Renesola, "Virtus ${ }^{\circledR I I}$ Module Datasheet."

[34] H. Eilers, "Thermoelectric (TECM) Cooling Holder," North West University, Potchefstroom, 2012.

[35] C. Svelto, G. Galzerano, G. Suardi, and E. Bava, "Compact and accurate digital thermometer based on an Anderson's loop and a Pt-100 sensor," in IMTC/99. Proceedings of the 16th IEEE Instrumentation and Measurement Technology Conference (Cat. No.99CH36309), vol. 3, pp. 1619-1623.

[36] N. Zabihi and R. Gouws, "Verifying the cooling capacity and power consumption of thermoelectric cooling holders for vaccine storage," in 2015 International Conference on the Domestic Use of Energy (DUE), 2015, pp. 115-119.

\section{BIOGRAPHIES OF AUTHORS}

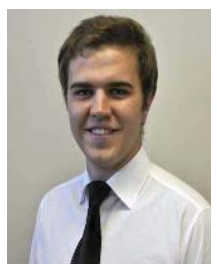

Henning Buitendach holds a Bachelor's degree in Electrical and Electronic Engineering from the North-West University (Potchefstroom campus). He is currently registered as a postgraduate student pursuing his Master's degree in Electrical and Electronic Engineering at the North-West University. His research is focused on the hypothesis that the efficiency of a PEM electrolysis system can be improved by applying a ripple wave, rather than the conventional steady DC, to the system. After graduation he worked as an engineer in training at Iritron. He is currently registered as a candidate engineer with the Engineering Council of South Africa (ECSA).

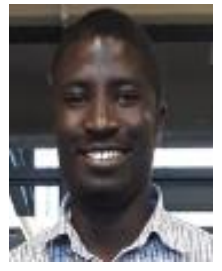

Immanuel Ninma. Jiya was born in Bida, Niger State, Nigeria in 1993. He received the B.Eng. degree in Electrical and Electronic Engineering from the Federal University of Technology, Minna, in 2016. And completed the M. Eng. degree in Electrical and Electronics Engineering at North-West University, Potchefstroom 2520, South Africa in 2018.

$\mathrm{He}$ is currently continuing his research career with a $\mathrm{PhD}$ degree in Electrical and Electronics Engineering at North-West University, Potchefstroom 2520, South Africa. His research current research area is Power Electronics with a special interest for energy storages, economics and management. 


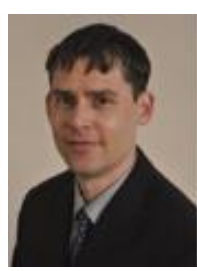

Rupert Gouws holds a Ph.D. degree in Electrical and Electronic Engineering from the North-West University (Potchefstroom campus). He consulted to a variety of industry and public sectors in South Africa and other countries in the fields of energy engineering and energy management. He is currently appointed as an Associate Professor specializing in energy engineering, electrical machines and control at the North-West University. The Engineering Council of South Africa (ECSA) registered him as a Professional Engineer and the Association of Energy Engineers (AEE) certified him as a Certified Measurement and Verification Professional (CMVP). 